\title{
POLÍTICA NACIONAL DE SAÚDE INTEGRAL À POPULAÇÃO LGBT: CONHECIMENTOS DE DISCENTES DA ÁREA DA SAÚDE
}

\section{NATIONAL POLICY FOR THE COMPREHENSIVE HEALTH OF THE LGBT POPULATION: HEALTH STUDENTS' KNOWLEDGE}

\author{
Nathália Ravadelli ${ }^{*}$; Janaina Samantha Martins de Souzall
}

\begin{abstract}
Resumo. Os movimentos sociais, liderados por grupos lésbicas, gays, bissexuais, travestis e transexuais (LGBT's), foram, dentre outros, os principais motivadores para a criação da Política Nacional de Saúde Integral (PNSI) de LGBT's. Mesmo com a melhora dos serviços, ainda há barreiras devido a um padrão de sociedade heteronormativa. Os desafios consistem na discriminação e falta de conhecimento por parte dos profissionais da saúde que carecem de preparo e conduta apropriada, o que culmina em atraso no direito à saúde dessa população. Tomando como base esta constatação, este estudo tem o objetivo de identificar o conhecimento dos discentes da área da saúde sobre a PNSI de LGBT's, e se eles estão aptos para atuar. Tratase de uma pesquisa descritiva/exploratória de caráter quantitativo, realizada com discentes da área da saúde do município de Caxias do Sul/RS por meio virtual. Foram entrevistados 70 discentes da saúde, através de um questionário semiestruturado. Sobre o informações acerca PNSI de LGBT, $57 \%$ referiram não obter conhecimento sobre a Política, enquanto $43 \%$ responderam que detinham algum tipo de referência. Quando questionados se alguma disciplina abordou a Política, $71 \%$ afirmaram que não foi apresentada em sala de aula, contrapondo-se a $29 \%$ dos discentes que responderam sim. Ressalta-se, de um modo geral, que a maioria dos entrevistados não têm embasamento teórico para atuar na prática com este determinado público e suas especificidades, portanto, é notório que o sistema institucional de educação preveja em grade curricular o estudo de políticas de minorias, permitindo que o discente detenha conhecimento teórico e saiba atuar na prática prestando um atendimento eficaz e humanizado.
\end{abstract}

PALAVRAS-CHAVE: Educação Superior. Minorias Sexuais e de Gênero. Política de Saúde.

Abstract. Social movements led by lesbian, gay, bisexual, transvestite and transgender (LGBT) groups, were among the main motivators for the creation of the National Policy for the Comprehensive Health (PNSI) of the LGBT population. Even with the improvement of services, there are still barriers due to a heteronormative society pattern. The main challenges consist of discrimination and lack of knowledge by health professionals, who lack knowledge and appropriate conduct, thus contributing to the delay in the right to health of this population. Thus, this study aims to identify the knowledge of health care students about the PNSI of the LGBT population and whether they are able to act. This is a descriptive/exploratory research of quantitative nature conducted with health students in the city of Caxias do Sul/RS by virtual means. 70 health students were interviewed using a semi-structured questionnaire. About the knowledge of the LGBT PNSI, 57\% reported having no knowledge about it, while $43 \%$ answered that they had some knowledge. When asked if any course had approached the policy, $71 \%$ said that it had not been presented in the classroom, however, $29 \%$ of the students answered that it had. It is noteworthy, in general, that most of the interviewees do not have the theoretical basis to act in practice with this public and its specificities, therefore, it is notorious that the institutional system of education provides in the curriculum the study of minority policies, allowing students to hold theoretical knowledge and to know how to act in their practice providing effective and humanized care.

KEYWORDS: Higher education. Sexual and Gender Minorities. Health Policy. 


\section{INTRODUÇÃO}

Mediante as lutas constantes
que assegurassem seus direitos de saúde integralmente, os movimentos sociais, liderados por grupos de lésbicas, gays, bissexuais, travestis e transexuais (LGBT's), foram, junto a outros, os principais motivadores para a criação da Política Nacional de Saúde Integral dessa comunidade. Além de objetivar romper alguns paradigmas da sociedade, os movimentos sociais também combatem diversas formas de violência como físicas, sexuais, psicológicas e preconceituosas. ${ }^{1}$

Através dessa política, houve um salto na qualidade dos serviços de saúde direcionados a essa população, entretanto, ainda há barreiras que eles encontram, devido a um padrão de sociedade heteronormativa. $^{2}$ Mesmo com criação da Política Nacional de Saúde Integral da população LGBT, instituída pela Portaria $\mathrm{n}^{\circ} 2.836$, de $1^{\circ}$ de dezembro de 2011 do Ministério da Saúde, ${ }^{3}$ alguns profissionais de saúde continuam agindo de forma discriminatória, não transformando - modo de pensar/agir, acarretando diversos atrasos no direito à saúde desses indivíduos.

Segundo Cardoso et al., ${ }^{4}$ uma postura reflexiva perante 0 padrão heterossexual que a sociedade estabelece, auxilia na prevenção da discriminação, o que evidencia a necessidade de uma formação de agentes de saúde que saibam lidar com as especificidades do público LGBT. Em vista disso, percebe-se que a comunidade LGBT carece de profissionais da saúde que sejam capazes de compreender as suas singularidades e que de fato possam realizar um atendimento com eficácia e qualidade. ${ }^{5}$

Partindo desse ponto, podese citar a graduação dos profissionais da saúde, que tem sido foco de críticas indiscutíveis, e justifica as questões levantadas sobre a formação nessa área. Um dos principais temas abordados é a matriz curricular, que se mantém inerte com conteúdo desconexo da realidade, o que dificulta assimilar a matéria teórica à prática diária, impossibilitando atender às necessidades de saúde da população e o desenvolvimento dela. ${ }^{6}$ Salientando a formação dos discentes da saúde, podemos citar em específico a graduação da Enfermagem, que teve as Diretrizes Curriculares Nacionais (DCN) aprovadas pelo MEC em 2001, o que estabeleceu habilidades e competências que definiam o perfil dos enfermeiros, promovendo uma formação que preenchia critérios generalistas, reflexivos e críticos. 6

Segundo Silva et al. ${ }^{6}$, a implementação dessa DCN permitiu que os profissionais da enfermagem pudessem impulsionar o cumprimento dos princípios doSUS, além de que através dela, a formação conseguiria atender de maneira mais abrangente às necessidades da população, garantindo a integralidade e humanização no tratamento prestado. Sendo assim, este trabalho objetivou identificar o conhecimento dos discentes da área da saúde sobre a PNSI de LGBT's, buscando assim, constatar as proximidades desses discentes com as políticas de saúde voltadas a essa população. 


\section{MATERIAL E MÉTODOS}

Trata-se de uma pesquisa descritiva/ exploratória com abordagem quantitativa, realizada por meio de um questionário on-line, no município de Caxias do Sul, no Estado Rio Grande do Sul. A escolha ocorreu para identificar o conhecimento dos discentes da saúde sobre a PNSI de LGBT. Foram entrevistados 70 discentes da saúde, através de um questionário semiestruturado.

$\mathrm{O}$ instrumento utilizado foi baseado em Ceciliano $^{5}$ e contou com perguntas abertas e fechadas. A coleta de dados ocorreu no período de março a maio de 2021, através do link compartilhando da plataforma do Google Forms, com discentes da área da saúde. Os respondentes, por meio de redes sociais, receberam o link do questionário de perguntas, junto com o termo de consentimento, dando garantia do anonimato. Ao autorizarem que as respostas fizessem parte do estudo, o

\section{RESULTADOS E DISCUSSÃO}

A maioria dos entrevistados eram do gênero feminino (90\%), de faixa etária entre 18 e 50 anos de idade, com predominância dos 21 aos 25 anos (35\%), classificou o estado civil como solteiro (a) $67 \%$, e discentes do curso de Bacharelado em Enfermagem $(64,5 \%)$ (Tabela 1). O que corrobora com os dados apresentados pelo Instituto Brasileiro de Geografia e Estatística (IBGE) ${ }^{7}$, em que as mulheres atualmente são a maioria das discentes em instituições de ensino superior e, conforme estatísticas analisadas em outro estudo8, o curso de Bacharelado em discente tinha acesso a um questionário, semiestruturado para autopreenchimento.

Após o período da busca por discentes interessados em responder aos questionários, os dados foram armazenados em planilha eletrônica, pelo programa Excel, para análise estatística descritiva, cujos resultados foram redigidos em forma de tabelas, sendo demonstrados neste trabalho de acordo com sua relevância. Diante disso, foi possível identificar as principais falhas no processo.

Este estudo foi aprovado pelo Comitê de Ética em Pesquisa da Associação Cultural e Científica Virvi Ramos, sob o Parecer $n^{\circ}$ 4.579.120 (CAAE: 42979221.0.0000.5523). Os pesquisadores seguiram as diretrizes e normas regulamentadoras preconizadas na Resolução N 466/12 do Conselho Nacional de Saúde sobre as pesquisas envolvendo seres humanos.

Enfermagem constitui-se no terceiro curso (251.450 discentes) em instituições privadas com mais matriculados.

Houve, neste estudo, uma predominância de indivíduos com ocupações distintas, a maioria delas exige média instrução/formação para ser exercida. As ocupações/profissões mais relatadas pelos discentes foram: estudante (39\%), técnico de enfermagem (14\%), secretaria (7\%), servidor público (4\%), empresária (4\%) e 32\% com outras ocupações. 
TABELA 1: Caracterização discentes da saúde $(n=70)$ do município de Caxias do Sul - RS, que participaram da pesquisa realizada por meio um questionário on-line.

\begin{tabular}{ccc}
\hline Variável & $\mathbf{N}^{\mathbf{0}}$ & $\%$ \\
\hline Gênero & & \\
\hline Feminino & 63 & 90 \\
Masculino & 7 & 10 \\
\hline Faixa etária & 14 & 20 \\
\hline $18-20$ anos & 24 & 35 \\
$21-25$ anos & 13 & 19 \\
$26-30$ anos & 11 & 16 \\
$31-35$ anos & 2 & 3 \\
$36-40$ anos & 4 & 6 \\
$41-45$ anos & 1 & 1 \\
$46-50$ anos & & 67 \\
\hline Estado Civil & 47 & 14 \\
\hline Solteiro & 10 & 17 \\
Casado & 12 & 2 \\
União estável & 1 & 64,3 \\
Divorciado & & 15,7 \\
\hline \hline Curso & 45 & 1,4 \\
\hline \hline Enfermagem & 11 & 4,3 \\
Fisioterapia & 1 & Fonte: dados da pesquisa. \\
Fonoaudiologia & 3 &
\end{tabular}

Quando questionados sobre de quanto era a renda mensal, responderam: $46 \%$ entre $R \$ 1045,00$ - 2090,00; 20\% referem não possuir renda; $14 \%$ relataram possuir renda mensal superior a $\mathrm{R} \$ 3135,00$; enquanto $10 \%$ possuem $R \$ 1045-2090$; e os outros $10 \%$ referem possuir renda igual ou inferior a $\mathrm{R} \$ 1.045,00$.

Sabe-se que em um estudo realizado em $2019^{9}$, a maioria dos discentes brasileiros (40\%) estava desempregado ou procurando emprego, 29,9\% eram estudantes que trabalhavam e $29,5 \%$ eram de estudantes que não trabalhavam (inativos), o que se assemelha com a ocupação dos discentes alvos desta pesquisa. Nesta mesma pesquisa, há a análise da renda mensal dos discente brasileiros, em que, relativamente, a maioria possui uma renda de 1-2 salários-mínimos, podendo variar para cada região do país.

A maioria dos discentes entrevistados possui 0 ensino superior incompleto, totalizando $84 \%$, e $16 \%$ completaram o ensino superior, fazendo a segunda graduação. Quando questionados sobre o semestre que estão cursando, $14 \%$ referem estar no $3^{\circ}$ semestre, $13 \%$ no $6^{\circ}$ semestre, $11 \%$ no $7^{\circ}, 10 \%$ no $8^{\circ}$ e $5^{\circ}$, seguidos por $9 \%$ no $2^{\circ}$ semestre, $7 \%$ no $1^{\circ}$ e $6 \%$ no $10^{\circ}$ semestre.

Quando questionados a respeito da crença, $47 \%$ referiram seguir a religião católica, seguidos com 20\% religião espírita, $7 \%$ se titulam ateus, $4 \%$ titulam-se evangélicos, umbandista e agnóstico, 3\% seguidores da religião luterana, protestante e cristã, 3\% referem não possuir religião e $1 \%$ 
titula-se como adventista.

A pesquisa demostrou que dos 70 entrevistados, 40 (57\%) deles não detinham qualquer conhecimento em relação as políticas de saúde voltadas a esse público, enquanto $43 \%$ (30), relatam conhecer a PNSI de LGBT. Quando questionados sobre por qual meio adquiriram o conhecimento, 53\% relataram não possuir conhecimento, $24 \%$ adquiriram através da internet, $15 \%$ durante a formação acadêmica, $4 \%$ através da televisão e $4 \%$ de outras formas, relata os entrevistados. Quando indagados se alguma disciplina ao longo da formação acadêmica abordou a temática, $71 \%$ responderam que não e somente $29 \%$ que sim, como mostra a
Tabela 2.

Isso coincide com a pesquisa de Ceciliano $^{5}$, em que os discentes de enfermagem, quando indagados sobre as políticas de saúde LGBT, a maioria $(78,68 \%)$ desconhecia totalmente esta política, sendo que poucos alegaram ter adquirido algum tipo de conhecimento sobre ela na vida acadêmica.

Neste contexto, questionou-se a importância da inclusão de conteúdos voltados a PNSI de LGBT, durante a formação acadêmica, sendo assim: 93\% dos discentes entrevistados referiram que há relevância na inclusão, enquanto somente $7 \%$ relatou não ser relevante.

TABELA 2: Conhecimento sobre a Política Nacional de Saúde Integral (PNSI) de LGBT entre discentes da saúde $(\mathrm{n}=70)$ do município de Caxias do Sul-RS, que participaram da pesquisa realizada por meio um questionário on-line.

\begin{tabular}{ccc}
\hline Variável & N $^{\circ}$ & $\%$ \\
\hline Conhecimento de discentes sobre as políticas voltadas a população LGBT \\
\hline Sim & 30 & 43 \\
Não & 40 & 57 \\
\hline Por meio de qual meio adquiriu conhecimento da PNSI de LGBT? & \\
\hline Não possuo conhecimento & 37 & 53 \\
Internet & 17 & 24 \\
Durante a formação acadêmica & 10 & 15 \\
Televisão & 3 & 4 \\
Outras formas & 3 & 4 \\
\hline \hline Alguma disciplina abordou essa política em sala de aula? & 29 \\
\hline Sim & 20 & 71 \\
Não & 50 & Fonte: dados da pesquisa.
\end{tabular}

Houve também um estudo que analisou o conhecimento de discentes e de enfermeiros sobre as especificidades LGBT, 33,34\% relatou sentir a necessidade de conteúdos voltados a população LGBT e maior explicação do significado da sigla, o que evidencia a necessidade de incluir as políticas voltadas a esta população em sala de aula. ${ }^{10}$

O presente estudo questionou os entrevistados sobre a opinião desses em relação aos serviços disponibilizados a população LGBT, $43 \%$ referiram não possuir conhecimento sobre o assunto, $26 \%$ consideram o serviço prestado como ruim, $24 \%$ consideram o serviço disponibilizado regular, $6 \%$ consideram um serviço bom e somente $1 \%$ como um serviço ótimo. Bem como, objetivou saber se na opinião dos discentes a política de saúde voltada a 
população LGBT, seria aplicada de forma eficaz, sendo assim: $60 \%$ dos discentes revelou não possuir qualquer tipo de conhecimento, $20 \%$ acreditam que é aplicada parcialmente, $17 \%$ presumem que ela não é aplicada de forma eficaz, enquanto somente 3\% afirma que sim, é eficaz.

Os autores Carvalho e Philippi, ${ }^{11}$ em sua pesquisa, evidenciam as dificuldades que a população LGBT encontra ao procurar serviços de saúde. Os principais entraves, segundo o próprio público, são pessoas despreparadas para atender a população LGBT, piadas e deboches (discriminação) cotidianos, espanto por práticas sexuais distintas, atendimento ginecológico discriminatórios, preconceitos com os problemas de saúde, falta de atenção com esta população, todos questionamentos que devem ser analisados a fim de proporcionar treinamentos adequados aos profissionais da saúde, buscando aumentar os saberes pertinentes a esta população, evitando profissionais despreparados e preconceituosos.

Isso ressalta a consideração de outro estudo, que destacou a limitação importante para a realização de programas e políticas LGBT, sendo justificada como ausência orçamentária para execução de ações previstas nos planos, afirmando que a escassez, bem como a ausência de recursos, é algo difícil de ser alcançado. ${ }^{1}$

Os discentes foram indagados se, como futuros profissionais da saúde, eles consideram-se aptos para atender as especificidades da população LGBT, nos quais $46 \%$ sentem-se parcialmente aptos para atender as especificidades dessa minoria, $30 \%$ consideram-se totalmente preparados, $18 \%$ relatam que teriam dificuldades e $6 \%$ não se consideram aptos para atender todas as demandas desta população em questão.

Baseando-se em uma temática similar com discentes da enfermagem, a maioria $(31,35 \%)$ revelam estar totalmente capacitados eaptos para atender as demandas da população LGBT, em menor quantidade (22,80\%), relatam que apresentariam dificuldades na hora do atendimento, enquanto $(14,03 \%)$ não sentem-se aptos para atender as especificidades da população LGBT, o que corrobora com o presente estudo, em que os dados não se distinguem em grande relevância, salientando, assim, a necessidade de capacitação dos futuros profissionais da saúde.

Isso ressalta a afirmação de uma pesquisa ${ }^{12}$ que evidenciou a pouca abordagem, ou a não abordagem sexual no processo de formação dos discentes da enfermagem, porém podemos aplicar para todos os cursos do presente estudo, que estão inaptos em relação a tal temática, necessitando adquirirem fundamentos suficientes sobre a sexualidade, em diferentes ciclos da vida para estarem capacitados a atuarem com determinada população. $\mathrm{O}$ autor desta mesma pesquisa12 relaciona a educação em saúde como um conceito de promoção a saúde, definindo amplamente como um processo que abrange toda a população em sua vida cotidiana e não somente a pessoa com risco de adoecer.

Corroborando com este pensamento, Pimenta e Hamann ${ }^{13}$ também presumem que a educação de profissionais da saúde deve ser reorientada, objetivando atender às necessidades integrais de indivíduos que, por muitas vezes, têm convívio, até mesmo com a família, negado, bem como os direitos reprodutivos e direitos sexuais.

Por fim, quando questionados sobre perguntas referentes a PNSI de LGBT, a maioria dos discentes da saúde (77\%) assinalou a alternativa certa sobre o objetivo geral desta política, enquanto o restante dos entrevistados (23\%) assinalou o objetivo 
errado referente a tal pesquisa. Quando questionados sobre de quem era o papel em conduzir a temática LGBT no âmbito da CIT (Comissão Intergestores Tripartite), 73\% dos entrevistados assinalaram a opção correta, MS (Ministério da Saúde), enquanto 27\% assinalaram a opção incorreta CNS (Conselho Nacional de Saúde) (Tabela 3).

Silva et al. ${ }^{14}$ analisaram a implementação da PNSI de $\mathrm{LGBT}^{15}$ no Paraná, que salienta o aprimoramento de métodos de vigilância em saúde, incluindo orientação sexual e de identidade de gênero. Também enfatiza a necessidade de educação em saúde para gestores e profissionais que, segundo o I Relatório Nacional de Saúde LGBT16, demonstrou a falta de capacitação deles, gerando a necessidade de maior diálogo e atuação do MS junto com o Ministério da Educação, com intuito de modificar os currículos dos cursos da saúde, visando formar profissionais capacitados para atuarem no atendimento à população LGBT e suas demandas.

TABELA 3: Conhecimento sobre objetivos e competência da Política Nacional de Saúde Integral (PNSI) de LGBT entre discentes da saúde $(n=70)$ do município de Caxias do Sul-RS, que participaram da pesquisa realizada por meio um questionário on-line.

\begin{tabular}{|c|c|c|}
\hline Variável & $\mathbf{N}^{\circ}$ & $\%$ \\
\hline \multicolumn{3}{|l|}{ Sobre o principal objetivo da PNSI LGBT, assinale a opção correta } \\
\hline $\begin{array}{l}\text { Promover a saúde integral da população LGBT, eliminando a discriminação e } \\
\text { preconceito institucional e contribuindo para a redução das desigualdades e } \\
\text { para consolidação do SUS como sistema universal, integral e equitativo }\end{array}$ & 54 & 77 \\
\hline $\begin{array}{l}\text { Integrar a população LGBT, diminuindo a discriminação e preconceito } \\
\text { institucional e contribuindo para a eliminando as desigualdades e para } \\
\text { consolidação do SUS como sistema universal, integral e equitativo. }\end{array}$ & 16 & 23 \\
\hline
\end{tabular}

Na sua opinião, conduzir os processos de pactuação sobre a temática LGBT no âmbito da CIT é uma competência de responsabilidade do:

\begin{tabular}{lrr}
\hline \hline Ministério da Saúde (MS) & 51 & 73 \\
\hline \hline Conselho Nacional de Saúde (CNS) & 19 & 27 \\
\hline
\end{tabular}

Visivelmente há necessidade de maior inclusão e transparência em assuntos relacionados à saúde LGBT em instituições de ensino superior, onde boa parte dos entrevistados demonstrou desconhecer as políticas voltadas a essa minoria, o que evidencia a importância de analisar e adicionar assuntos pertinentes nas grades curriculares, promovendo o aperfeiçoamento dos discentes da saúde e proporcionando uma melhora no atendimento ao público LGBT.

\section{CONCLUSÃO}

A pesquisa possibilitou analisar - conhecimento dos discentes da área da saúde em relação as políticas públicas voltadas a saúde LGBT, o que demonstrou que os discentes detêm algum nível de embasamento teórico, porém necessitam de maiores proximidades com políticas públicas voltadas a esta minoria. 
Reforça-se a necessidade da análise dos currículos dos cursos da área da saúde, que permanecem inertes as mudanças da sociedade, baseando-se em padrões heteronormativos que corroboram para o despreparo dos futuros profissionais, e de certa forma, com o preconceito institucional ao não abordar a temática.

\section{REFERÊNCIAS BIBLIOGRÁFICAS}

1. Borges AT, Estrela NMF, Felix MOSD. Políticas de saúde para lésbicas, gays, bissexuais, travestis e transexuais no Brasil: em busca de universalidade, integralidade e equidade. Anais do II Seminário Nacional de Serviço Social, Trabalho e Políticas Sociais; 2017; Florianópolis, SC.

2. Sousa PJ, Abrão FMS, Costa AMC, Ferreira LOCF. Humanização no acolhimento de gays, lésbicas, bissexuais, travestis e transexuais na atenção básica: reflexões bioéticas para enfermagem. Anais do Segundo Seminário Nacional de diretrizes para enfermagem na atenção básica em saúde; 2009 nov. $1-3$.

3. Ministério da Saúde (Brasil). Portaria $n^{\circ} 2.836$, de $1^{\circ}$ de dezembro de 2011. [internet] Brasília; 2021 [citado em 2021 Jun 06]. Disponível em: https://bvsms.saude. gov.br/bvs/saudelegis/gm/2011/prt2836_01_12_2011. html

4. Cardoso MR, Ferro LF. Saúde e população LGBT: demandas e especificidades em questão. Psicol. Ciên. Prof. 2012; 32(3): 552-63.

5. Ceciliano LA. Conhecimento de estudantes em enfermagem da Política Nacional de Saúde Integral de Lésbicas, Gays, Bissexuais, Travestis e Transexuais [Monografia]. Brasília: Centro Universitário de Brasília, Faculdade de Ciências da Educação e Saúde; 2015.

6. Silva FM, Vilela AL. Homo (lesbo)erotismo e literatura, no Ocidente e em Portugal: Safo e Judith
Espera-se que, através desta pesquisa, as instituições de ensino com cursos da saúde, possam analisar e acrescentar assuntos pertinentes ao conhecimento de práticas voltadas a população LGBT, incluindo as políticas e a assistência prestada a estes cidadãos.

Teixeira. Navegações. 2011; 4(1): 69-76.

7. Instituto Brasileiro de Geografia e Estatística (Brasil). Estatística de gênero: indicadores sociais das mulheres no Brasil. [internet] 2021 [citado em 2021 Jun 06]; 1-12. Disponível em: https://biblioteca.ibge. gov.br/visualizacao/livros/liv101784_informativo.pdf.

8. Instituto Nacional de Estudos e Pesquisas (Brasil). Censo da educação superior 2019. [internet] 2020 [citado em 2021 Jun 06]; 1-82. Disponível em: https:// download.inep.gov.br/educacao_superior/censo superior/documentos/2020/Apresentacao_Censo_ da_Educacao_Superior_2019.pdf.

9. Fórum Nacional de Pró-Reitores de Assuntos Estudantis. $\vee$ Pesquisa Nacional de Perfil Socioeconômico e Cultural dos (as) Graduandos (as) das IFES - 2018. [internet] 2019 [citado em 2021 Jun 06]; 1-158. Disponível em: http://www.fonaprace. andifes.org.br/site/wp-content/uploads/2019/06/VPesquisa-do-Perfil-Socioecono\%CC\%82mico-dosEstudantes-de-Graduac\%CC\%A7a\%CC\%830-das-U.pdf.

10. Torres RC, Sousa PHSF, Silva MML, Azevedo MVC, Morais ALDJ, De Andrade AFSM et al. Conhecimento de discentes e enfermeiros acerca da política nacional dos direitos LGBT+. Brazil. J. Develop. 2020; 6(10): $75032-43$.

11. Carvalho LS, Philippi MM. Percepção de lésbicas, gays e bissexuais em relação aos serviços de saúde. Universitas: Ciênc. Saúde. 2013; 11(2): 83-92. 
12. Teodoro IPP, Felipe NKS, Teodoro LPP. Percepção das mulheres homoafetivas frente a assistência de enfermagem na saúde da mulher. Id on line Rev. Psicol. 2014; 8(22): 130-44.

13. Pimenta FA, Hamann EM. Uso dos serviços de saúde por parte de homens que fazem sexo com homens do Distrito Federal. Tempus - Actas de Saúde Col. 2011; 35-53.

14. Silva ACA, Alcântara AM, Oliveira DC, Signorelli MC. Implementação da Política Nacional de Saúde Integral de Lésbicas, Gays, Bissexuais, Travestis e Transexuais (PNSI LGBT) no Paraná, Brasil. Interface
(Botucatu). 2020; 24: e190568.

15. Ministério da Saúde (Brasil). Política Nacional de Saúde Integral de Lésbicas, Gays, Bissexuais, Travestis e Transexuais. [internet] 2013 [citado em 2021 Jun 6]; 1-36. Disponível em: https://bvsms. saude.gov.br/bvs/publicacoes/politica_nacional_ saude_lesbicas_gays.pdf.

16. Ministério da Saúde (Brasil). Relatório do I Seminário Nacional de Saúde LGBT. [internet] 2013 [citado em 2021 Jun 6]; 1-36. Disponível em: https:// bvsms.saude.gov.br/bvs/publicacoes/relatorio_ semniario_nacional_saude_lgbt.pdf. 